\title{
Calidad científica, temáticas e impacto nacional de las publicaciones radiológicas en Colombia (2005 -2013)
}

Scientific quality, thematic and national impact of radiological publications in Colombia (2005 -2013)

Nelson Ricardo Ávila Meneses ${ }^{1}$, Aracely Burgos Ayala² \& Nelly Yolanda Céspedes ${ }^{3}$

\section{Resumen}

Objetivos. (i) Caracterizar la ciencia radiológica que se produce en Colombia, durante el periodo en estudio, (ii) Evidenciar las temáticas radiológicas más estudiadas y, (iii) Reconocer la credibilidad entre colegas científicos radiólogos colombianos (impacto nacional). Metodología: se revisaron las publicaciones de la RCR entre 2005 - 2013; para el primero y segundo objetivo se totalizó y hallaron porcentajes, para el tercero, se aplicó el índice de impacto. Resultados: Se encontró que en Colombia se escribe suficientemente sobre radiología, predominan los artículos y revisiones de caso, lo que menos se publica son resultados de investigación.

Palabras clave: radiología, investigación, ciencia, Colombia, temáticas, impacto.

\begin{abstract}
Objectives. (i) To characterize the radiologic sciences produced in Colombia, (ii) To demonstrate the most studied and radiological Theme (iii)To Recognize credibility among fellow scientists radiologists Colombians (national impact). Methodology. RCR publications were reviewed between 2005-2013, for the first and second target will be totaled and percentages found, for the third, an impact factor was applied. Results. We found that in Colombia you write enough about radiology predominate articles and case reviews, which are less published research results.
\end{abstract}

Keywords: radiology, research, science, Colombia, theme, impact.

\footnotetext{
1 Médico Cirujano, U. Nacional. Magister en gestión y dirección de instituciones educativas. U. Internacional de la Rioja. Director del Programa de Tecnología en Radiología e

2 MSc en Ciencias, U. de Chile. Investigadora Grupo Radioprotección Colombia, Fundación Universitaria del Área Andina; Docente, Fundación Universitaria Juan de Castellanos.

3 Estudiante de doctorado en Educación, U. Santo Tomás. Docente del Programa de Tecnología en Radiología e Imágenes Diagnósticas, Fundación Universitaria del Área Andina. Investigadora del Grupo Radioprotección Colombia.

Correspondencia: ravilam12@gmail.com

Recibido: 13/06/2015 Aceptado: 25/06/2015
} 


\section{Introducción}

Hacer ciencia, básica o aplicada, consiste en buscar y producir nuevo conocimiento, y a partir de ello, establecer leyes (1). La radiología desarrolla ciencia aplicada en varias áreas, entre ellas, la salud, a través de la producción de imágenes diagnósticas obtenidas por medio de diferentes técnicas que sirven a diversas especialidades médicas, técnicas cómo la mamografía (2), la radiología oral (3), el ultrasonido (4), la radioterapia (5), la tomografía computarizada (4), la resonancia magnética (4), entre otras, a partir de estas se detecta, diagnostica y hace seguimiento a diversas patologías (5).

Las ciencias radiológicas ingresaron a Colombia años después de su desarrollo e implementación mundial. Por ejemplo, la Xeroradiografía, método radiológico oral, inició su implementación hacia 1937 (6) y a Colombia llegó hasta 1980 (5). Esta situación, que se repitió en las diversas técnicas, presupone cierta desventaja y retraso de quienes producen ciencia en este campo en el país.

La producción científica se evidencia y reconoce, en términos de calidad, a través de la publicación en revistas científicas, para el área de radiología en Colombia se publica, en mayor medida, en la Revista Colombiana de Radiología (RCR) órgano de la Asociación Colombiana de Radiología (ACR), y creada en el año de 1998 (7). Hasta el momento, esta es la única revista que ha tenido categorización en la temática de la imagenología por el Î́ndice Bibliográfico Nacional Publindex de Colciencias, el cual jerarquiza las revistas científicas colombianas en $A_{1}, A_{2}, B$ y $C$, de mayor a menor respectivamente, según la calidad científica, editorial, estabilidad, visibilidad y reconocimiento nacional e internacional (8); la RCR estuvo catalogada en B hace unos años (9) y actualmente está en proceso de Indexación, lo que implica un reconocimiento importante de su contenido científico.

La calidad científica, principal criterio de categorización de Publindex, se mide por el tipo de artículos publicados y los clasifican como: de investigación, revisión, reflexión, reportes de caso y artículo corto; de estos, tan sólo los de investigación dan cuenta de avances científicos propiamente, los demás, si bien son importantes y necesarios, no constituyen un aporte al desarrollo de la ciencia. Esto es relevante para Colombia, si se compara con países como Chile, considerado uno de los países avanzados en producción científica a nivel latinoamericano $(10,11)$, en donde los porcentajes de artículos producidos en radiología presentan una tipología así: revisiones de tema (32\%) y reportes de caso $(15 \%)$ son los que predominan y tan solo el $11 \%$ corresponde a investigación propiamente dicha (12). Al respecto, cabe realizar la pregunta ¿Qué cantidad de investigación radiológica se produce y publica en Colombia?

La editorial, la estabilidad y visibilidad de la RCR se puede constatar a través de su sitio web, donde a partir del año 2005 , de forma libre se puede ingresar a todas las editoriales y publicaciones (7), así se evidencian éstos tres requisitos evaluados por Publindex.

Otro aspecto, seguramente ha aportado la categorización a la RCR, y es el reconocimiento o impacto nacional e internacional de sus publicaciones, el cual es expresado a través de la cantidad de veces que se son citados los artículos en Colombia (impacto nacional) y fuera del país (impacto internacional). Sin embargo, este dato se desconoce para la RCR. El impacto nacional es el interés en este artículo, dado que si publicaciones como la "Revista Chilena de Radiología” que divulga el 82\% de lo producido en radiología en ese país, encontró que en un año los colegas radiólogos chilenos apenas lograron citar entre 1 y 8 artículos publicados en esta misma revista en el año inmediatamente anterior, de aproximadamente 36 que se producen al año (12), cabe aquí preguntarse ¿Cuál es el impacto nacional de la producción científica radiológica en Colombia?; esto es, qué tanto se leen, citan y confían en la ciencia producida por los colegas radiólogos del país. 
Adicionalmente, en Colombia se desconocen las temáticas de interés científico más recurrentes en radiología, así como su intensidad. Esta información resulta clave para priorizar campos de investigación radiológica requeridos según las capacidades de investigadores radiólogos en Colombia, así como para priorizar desafíos necesarios, inexplorados y factibles de investigar por la comunidad científica radiológica colombiana.

Lo anteriormente expuesto permite desarrollar los tres objetivos en este documento 1-) Caracterizar la ciencia radiológica que se produce en Colombia -calidad científica-, 2-) Evidenciar las temáticas radiológicas más estudiadas y, 3-) Reconocer la credibilidad existente entre colegas científicos radiólogos colombianos -impacto nacional-. Los tres objetivos se basarán en las publicaciones de la RCR a partir del año 2005 hasta el primer semestre del 2013.

\section{Materiales y métodos}

La metodología general se apoyó en la investigación realizada por Canals (12) en Chile. Para los tres propósitos de esta investigación se hizo revisión la de todos los artículos de la RCR publicados entre el 2005 y el 2013, a través de su base de datos de libre acceso (Z). Para el primer y segundo objetivo la información de cada artículo se tabuló en el programa Microsoft Excel 2007 (Microsoft Office ${ }^{\oplus}$ ); en las columnas se ubicaron las variables año, volumen, número, tipo de artículo (original, de investigación, de revisión, serie de caso, presentación de caso, educación, reporte de caso, nota, otros) y tema, éste último se logró a partir de la lectura de los artículos y las palabras clave. En las filas se ubicaron los datos de cada artículo, donde se asignó con el número "1" en el lugar donde los datos obtenidos de cada artículo revisado. En cada columna se totalizó y hallaron los porcentajes. Adicionalmente, en los artículos de investigación, se identificó si tenían objetivo definido, hipótesis, así como el tipo de estadística utilizada.
Para el reconocimiento del impacto nacional, tercer objetivo, igualmente se usó el programa Microsoft Excel 2007 (Microsoft Office ${ }^{\circledR}$ ); en las filas se ubicó la variable año, desde el 2005 hasta el primer semestre del 2013; en cada fila se indicó el número de artículos de la RCR que fueron citados en la misma revista en el ańo inmediatamente anterior. Aquí se usó el índice de impacto:

$$
I_{i}=\operatorname{ac}_{/ a p} i-1, i+2
$$

Donde:

$\mathbf{I}_{\mathbf{i}}=$ es el índice de impacto del año " $\mathrm{i}$ ”

$\mathbf{a c}=$ es el número de artículos citados en la revista

ap $_{\mathrm{i}-1, \mathrm{i}+2}=$ es el número de artículos publicados en la revista en los dos años anteriores

Este índice es una variante del índice de impacto usado habitualmente en las revistas del Science Citation Index (SCI), que considera en el numerador de los artículos citados que hayan sido publicados en cualquier revista, pero en los dos años anteriores $\left(\mathrm{ac}_{\mathrm{i}-1, \mathrm{i}+2}\right)$

\section{Resultados}

En total se revisaron 270 artículos publicados a través de 9 volúmenes y 33 números, divulgados entre los ańos 2005 y el primer semestre del 2013.

\section{Calidad científica radiológica}

La clasificación usada en esta investigación se hizo respecto a la misma que desarrolla la revista. De los 8 tipos de artículos que publica la RCR, predominan los de presentación de caso (25.5\%) y revisión de caso (23.7\%); lo catalogados como serie de caso y reporte de caso tuvieron menor representatividad, con 8,8 y $12,9 \%$ respectivamente. Los de investigación $(3,7 \%)$ y los de educación (2.59\%) son los que menos se publican, Figura 1. 


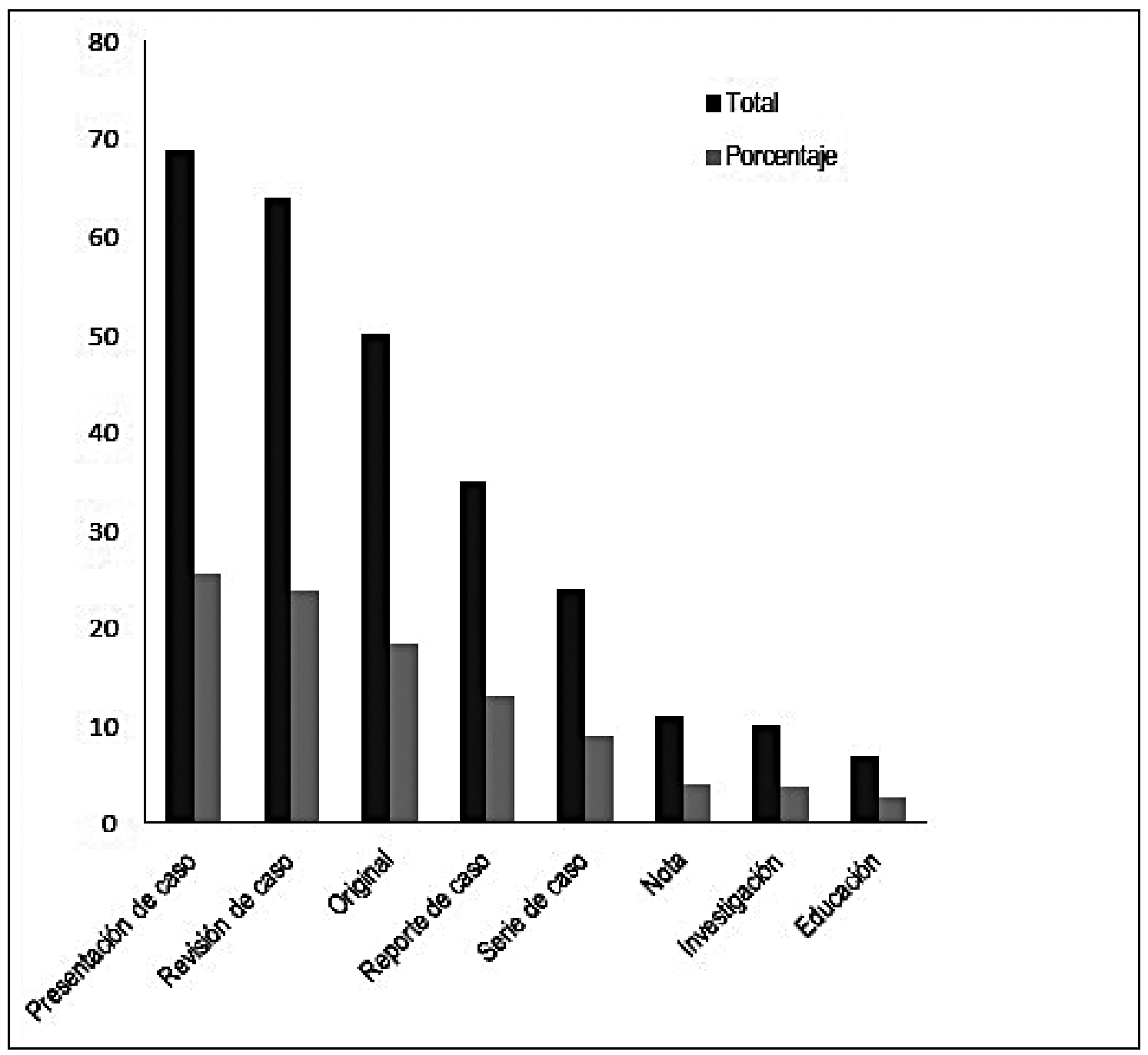

Figura 1. Tipos de artículos publicados en la Revista Colombiana de Radiología (RCR) entre el 2005 y el primer semestre del 2013 (Total 270 artículos). En color obscuro se indican los porcentajes, en gris el número de artículos.

\section{Temáticas de interés abordadas}

Las temáticas de mayor interés fueron encefalopatía (19,6\%), conducto pancreático y patología de la mama con un $11 \%$ cada una; las demás áreas que se reportaron más de una vez tuvieron representación menor al 9.8\%: se encontraron 44 temas que tan sólo se publicaron en una oportunidad (86\%), estas temáticas fueron llamadas como "otros" en la Tabla 1. 
Tabla 1. Temáticas de interés publicadas en los artículos de la Revista Colombiana de Radiología (RCR) entre el 2005 y el primer semestre del 2013.

Temática (Áreas y especialidades)

\section{Estenosis}

Radiografía de tórax

Colédoco

Resonancia magnética

Arteria carótida en tomografía

Ultrasonido

Tomografía computarizada

Reporte mamográfico

Aneurisma por RM

Otros

Total

Las técnicas que más se abordaron fueron la tomografía computarizada (24\%), la resonancia magné-
Número de publicaciones

PORCENTAJE $\%$

0,7

8,1

0,7

23,0

1,9

17,0

24,1

2,2

1,1

21,1

270

100 tica $(23,7 \%)$, seguidas por la ecografía $(10,3 \%)$ y la radiografía de tórax $(8,14 \%)$, Figura 2 .

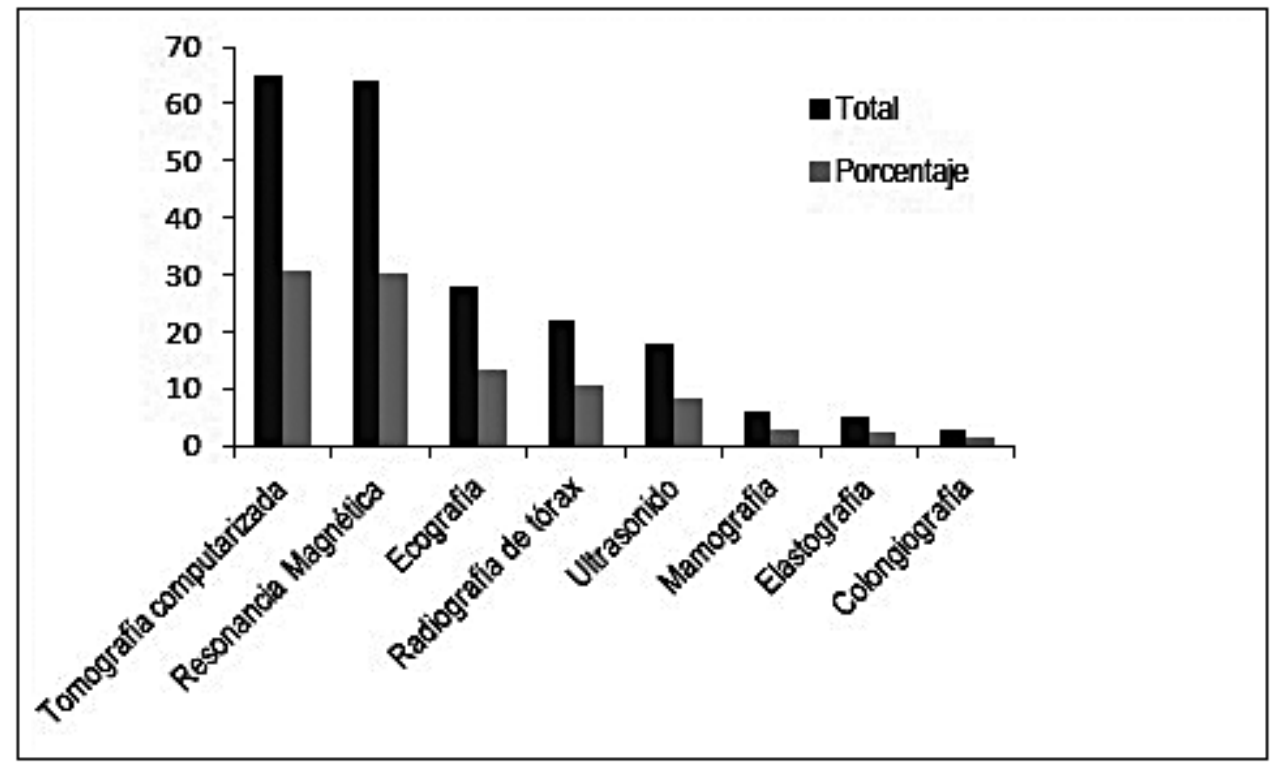

Figura 2. Técnicas de interés publicadas en los artículos de la Revista Colombiana de Radiología (RCR) entre el 2005 y el primer semestre del 2013. En color obscuro se indican los porcentajes, en gris el número de artículos. 
De los 10 artículos de investigación, las áreas de interés fueron: arterias coronarias, patologías vasculares, función cerebral, enfermedad pulmonar, patologías de la mama y tendones, y en seis de los artículos se recurre a la técnica de resonancia magnética. Ninguna de estas investigaciones tenían hipótesis y sólo 5 (50\%) tenían objetivos definidos; respecto a la estadística aplicada, 5 tenían porcentajes y 5 no tenían ningún tipo de estadística. Llama la atención la ausencia de pruebas de hipótesis y estadísticas sin intervalos de confianza.

\section{Impacto nacional}

Este aspecto sería evaluado a través del Índice de Impacto, el cual requería el número de artículos de la RCR citados en la misma revista en los dos años inmediatamente anteriores. Tal índice no se pudo hallar debido a que en ningún año se encontraron citaciones de los dos años anteriores; tan solo en los años 2011, 2012 y 2013 se evidenció una citación en alguno de sus artículos, pero éstos eran de más de dos años, 2002 y 2009. Sin embargo, se resalta que con frecuencia se citan las editoriales, especialmente entre los ańos 2005-2009.

\section{Discusión}

Esta investigación se centró en: la calidad científica radiológica que se produce en Colombia, las temáticas más estudiadas y la credibilidad existente entre colegas científicos radiólogos colombianos -impacto nacional- según las publicaciones de la Revista Colombiana de Radiología entre el 2005 y el primer semestre del 2013.

\section{Calidad científica radiológica}

Los artículos revisados corresponden al 36\% de la producción de la RCR, y corresponde a lo divulgado entre el 2005 y el primer semestre del 2013, así, la muestra tomada (270 artículos) resulta representativa.

Se parte del hecho de que el conocimiento se construye y valida socialmente (14), en este sentido, la RCR ha desarrollado su misión de difundir y elevar la calidad de la producción científica en el área de imágenes diagnósticas y sus disciplinas afines en Colombia. Si bien la clasificación de los artículos que tiene Publindex es específica, la RCR muestra una diversidad en cuanto a su tipología de publicaciones, similar ocurre en la Revista Chilena de Radiología (11), Tabla 2. La relevancia de esta clasificación cobra fuerza en la medida que, por ejemplo, para Publindex, tan solo los tres primeros tipos de artículos son válidos para la indexación de las revistas y que son éstos los que aportan y dan cuenta del avance científico. Entonces, ¿los demás no aportan a la ciencia? Según Delgado (14) la ejecución de cierto tipo de investigaciones resulta muy costosa en medios latinoamericanos, y que un reporte o serie de caso pueden presentar una condición única y servir de base para investigaciones futuras. En el análisis de la RCR, se encontró una mayor tendencia a escribir sobre presentaciones y reportes de caso, lo que podría inferir que prevalecen los proyectos prácticos y de estudio; las series y reportes fueron los que menos se encontraron.

Los artículos de investigación en la RCR, son los segundos de menor gusto por los autores colombianos (10 de 270, el 3,7\%), el primer lugar lo ocupan los de educación (2.59\%) y es tan solo a partir del 2007 cuando se visualizan los de investigación. Y si sólo a través de estas publicaciones se da cuenta del avance científico de la radiología en Colombia, la situación se torna en crítica, más aún, al compararla con cifras de artículos de la misma tipología en países como Chile, donde la investigación radiológica es del 11,2\% (de 277 artículos) y aun así se considera baja (12). 
Tabla 2. Tipos de artículos según Publindex (2013), la Revista Chilena de Radiología (1997-2005) y la Revista Colombiana de Radiología (2005-2013).

\section{Publindex}

Revista Colombiana de Radiología

De investigación científica y tecnológica

De investigación

De investigación

De reflexión

De revisión

Corto

Reporte de caso

Reporte de caso

Reporte de caso

Revisión de tema

Revisiones de tema

Documento de reflexión no derivado de investigación

Cartas al editor

De opinión

Casos de desafío

Revisión de caso

Historia de la radiología

Docentes

De Educación

Técnicos

De experiencia

Presentación de caso

Originales

Serie de caso

Notas

Lo anterior sugiere que si bien a la RCR se le avalan esfuerzos en la calidad de sus publicaciones al estar en categoría B en Publindex hacia 2012, ocurre la necesidad de fortalecer los procesos científicos del país en temas de radiología. Lo anterior se complementa con lo expuesto en una de las editoriales de la RCR titulada ¿Por qué no escribimos?, allí se sugiere que son algunos comportamientos, actitudes y temores los que impiden el logro de la comunicación escrita resultado de productos de investigación los que son visibles y admirables en escenarios de comunicación oral (13). En la misma editorial se pide valorar el esfuerzo para realizar una investigación y no ser finalizada en su difusión, e invita a tomar como medida el que toda investigación culmine en una publicación, ya sea para otros medios de divulgación, o para la RCR y así contribuir a mantener y mejorar la clasificación, más aún, al demostrarse en la RCR que a través del tiempo los documentos de investigación ha iniciado una tendencia a incrementarse, o como una simple cuestión ética del investigador radiólogo. 


\section{Temáticas de interés abordadas}

Un resultado relevante es reconocer que la encefalopatía es la principal temática de interés publicada, seguida por patologías del conducto pancreático y la patología de la mama, sin embargo no se puede inferir que estas sean las patologías de mayor prevalencia en los pacientes a quienes se les ordenan imágenes diagnósticas en el país. La tendencia por escribir más sobre la encefalopatía podría estar en función más que de la prevalencia, del gusto personal de los investigadores, o de su misma especialidad. Otras áreas que despiertan el interés científico de los radiólogos son la arteria carótida, la esclerosis sistémica, la hidrocefalia y el cáncer de próstata con $9.8 \%$ de escritura cada una; así, estas patologías son los principales intereses de escritura, sin embargo, no existe relación clara en la intensidad de investigación y la prevalencia de dichas patologías en el país. Otros 44 temas (86\%) fueron abordados solamente en una oportunidad, esto podría indicar que la radiología es un campo muy diverso, tema que merece profundización.

Al revisar las técnicas sobre las cuales más escriben los radiólogos, se encontró que la tomografía computarizada y la resonancia magnética son las preferidas, esta última coincide en artículos de investigación. Esto indica un interés por abordar la alta tecnología, por las prestaciones en definición y precisión diagnóstica.

\section{Impacto Nacional}

Desafortunadamente, pareciera que la revista no logra un impacto a nivel nacional, pues los autores de los artículos revisados entre el 2005 y el 2007 no referencian publicaciones divulgadas en ella misma. Respecto a este aspecto hay varios aspectos por analizar.

Al revisar los artículos de la RCR se visualiza una riqueza, esfuerzo e interés de diversas entidades y profesionales relacionados con la radiología en Colombia. Igualmente se percibe el esfuerzo editorial en hacer que la revista sea amena, entretenida y que genera motivación para leerla y publicar en ella, hay que sumarle una bonita presentación. Adicional, la calidad científica ha llegado a niveles de reconocimiento, ser B en Publindex. Entonces ¿Por qué los radiólogos no se citan entre ellos, al menos en lo que respecta a esta revista?; en revistas como la Chilena de Radiología, bajo las mismas características, se logra una citación de 1 a 8 artículos al año. Una posible explicación estaría en función del reconocimiento que se da a revistas de alto impacto a nivel internacional en temas radiológicos, lo que se evidenció al revisar las referencias de los artículos. Adicional, el hecho de que haya poca investigación en el país, o al menos la que se publica, puede reducir la confianza o interés en citarse mutuamente. Sin embargo, se requieren estrategias para valorar la ciencia que se produce en el país, con acciones desde la academia, las editoriales, las universidades y porque no, desde las políticas en educación, salud y en tecnologías de investigación que fomenten el producir y divulgar, de forma oral y escrita, producción científica radiológica del país.

Respecto a la RCR, se sugiere analizar y hacer pública la encuesta de satisfacción de análisis de opinión de los radiólogos en relación al contenido de la RCR, además de conocer que tanto publican en otras revistas y contribuyen al conocimiento radiológico en el país.

Como conclusión, en Colombia se escribe suficientemente sobre radiología; predominan los artículos y revisiones de caso y, lo que menos se publica, son resultados de investigación; esto no quiere decir que no se investigue, pero sí que poco se publica. Las comunicaciones científicas orales (ej. congresos), que en mucho se presentan en el país, evidencian que si se produce ciencia radiológica en Colombia, la cuestión es que no se están divulgando. De lo que se divulga prevalecen ciertas temáticas desarrolladas a través de diversas técnicas, tal vez por su importancia, su prevalencia o su facilidad de acceso, esto se desconoce; adicionalmente, en las 
investigaciones se requiere fortalecer la definición de objetivos, el diseño experimental y la estadística usada, aspectos relevantes en toda investigación. Finalmente, es urgente implementar estrategias de credibilidad entre radiólogos de Colombia.

\section{Agradecimientos}

Esta investigación fue apoyada por el Centro de Investigación y Desarrollo (CID) de la Fundación Universitaria del Área Andina.

\section{Referencias}

1. Bunge M. Philosophical Doctionary. New York. Promeheus Books. 1999. p. 258.

2. Cruz E. Seminario sobre mamografía. Bogotá: Fundación Universitaria del Área Andina, programa de Tecnología en Radiología e Imágenes diagnósticas. Material no publicado. 2005.

3. Haring J., Lind, L. Radiología Dental: Principios y Técnicas. McGraw Hill. D.F., México.

4. Ortega D., Seguel. Historia del ultrasonido: el caso chileno. Revista Chilena de Radiología. 2004; 10 (2), 89-92. [citado 2014, Feb 13] Disponible en: http://www.scielo.cl/scielo. php?pid=S0717-93082004000200008\&script=sci_arttext

5. Pico E. Historia y procedimientos de la imagenología diagnóstica en el campo de la salud. Ed. Fundación Universitaria del Área Andina. Bogotá. 2009. 474p.
6. Ramírez L. Visión Actualizada de la Radiología en Endodoncia. Universidad Central de Venezuela [citado 2013 Sept 20]. Disponible en: http://www.carlosboveda.com/ Odontologosfolder/odontoinvitadoold/odontoinvitado_20.htm

7. Asociación Colombiana de Radiología [internet]. Octubre 2013 [citado 2014 Oct 20]. Disponible en: www.acronline.org

8. Documento Guía Servicio Permanente de Indexación de Revistas de Ciencia, Tecnología e Innovación Colombianas,. Departamento Administrativo de Ciencia Tecnología e Innovación. Sistema Nacional de Indexación y Homologación de Revistas Especializadas I+D, Publindex. 2010.

9. Sistema Nacional de Indexación y Homologación de Revistas Especializadas I+D, Publindex, 2013 [citado 2013, May 06] Disponible en: http://scienti.colciencias.gov. co:8084/publindex/EnIbnPublindex/resultados.do,

10. Miguel S. Revistas y producción científica de América Latina y el Caribe: su visibilidad en SciELO, RedALyC y SCOPUS. Revista Interamericana de Bibliotecología. 2011; 34(2): 187-199.

11. Ministerio Nacional de Educción, Colombia [internet]. Septiembre 2013. [citado 2014 En 29] http://www.mineducacion.gov.co/sistemasdeinformacion/1735/w3-article-245356.html

12. Canals M. Ciencia e Imaginología: Análisis cuantitativo de la investigación radiológica. Revista Chilena de Radiología. 2008; 14 (4): 221-226.

13. Bermúdez S. ¿Por qué no escribimos?. Editorial, Revista Colombiana de Radiología. 2013; 23(3): 3519-20.

14. Delgado J. ¿Qué tipos de artículos publicar en una revista científica? Una reflexión sobre los reportes de caso. Editorial, Revista Universitaria Odontológica. 2012; 31(67): $13-14$ 